OPEN ACCESS

Edited by:

Corina Vlot,

Helmholtz Zentrum München,

Germany

Reviewed by:

Madhaiyan Munusamy,

Temasek Life Sciences Laboratory,

Singapore

Fanhong Meng,

Texas A\&M University, United States

*Correspondence:

Gilles Cellier

gilles.cellier@anses.fr

Specialty section: This article was submitted to

Plant Microbe Interactions,

a section of the journal

Frontiers in Plant Science

Received: 17 February 2017 Accepted: 02 May 2017

Published: 24 May 2017

Citation:

Cellier G, Arribat S, Chiroleu F, Prior P and Robène I (2017) Tube-Wise Diagnostic Microarray for the Multiplex Characterization of the Complex Plant

Pathogen Ralstonia solanacearum. Front. Plant Sci. 8:821

doi: 10.3389/fpls.2017.00821

\section{Tube-Wise Diagnostic Microarray for the Multiplex Characterization of the Complex Plant Pathogen Ralstonia solanacearum}

\author{
Gilles Cellier ${ }^{1 *}$, Sandrine Arribat ${ }^{2}$, Frédéric Chiroleu ${ }^{2}$, Philippe Prior ${ }^{2,3}$ and \\ Isabelle Robène ${ }^{2}$ \\ ${ }^{1}$ Tropical Pests and Diseases Unit, Plant Health Laboratory, ANSES, Saint-Pierre, France, ${ }^{2}$ UMR Peuplements Végétaux et \\ Bioagresseurs en Milieu Tropical, CIRAD, Saint-Pierre, France, ${ }^{3}$ Département Santé des Plantes et Environnement, Institut \\ National de la Recherche Agronomique, Saint-Pierre, France
}

Ralstonia solanacearum is a well-known agricultural and ecological threat worldwide. The complexity of the $R$. solanacearum species complex (Rssc) represents a challenge for the accurate characterization of epidemiological strains by official services and research laboratories. The majority of protocols only focus on a narrow range of strains; however, this species complex includes strains that represent major constraints and are under strict regulation. The main drawback associated with the current methods of detecting and characterizing Rssc strains is their reliance on combining different protocols to properly characterize the strains at the ecotype level, which require time and money. Therefore, we used microarray technology (ArrayTube) to develop a standard protocol, which characterizes 17 major groups of interest in the Rssc, in a single multiplex reaction. These 17 majors groups are linked with a phylogenetic assignation (phylotypes, sequevars), but also with an ecotype assignation associated with a range of hosts (e.g., brown rot, Moko). Probes were designed with a 50-mer length constraint and thoroughly evaluated for any flaws or secondary structures. The strains are characterized based on a DNA extraction from pure culture. Validation data showed strong intra-repeatability, inter-repeatability, and reproducibility as well as good specificity. A hierarchical analysis of the probe groups is suitable for an accurate characterization. Compared with single marker detection tests, the method described in this paper addresses efficiently the issue of combining several tests by testing a large number of phylogenetic markers in a single reaction assay. This custom microarray (RsscAT) represents a significant improvement in the epidemiological monitoring of Rssc strains worldwide, and it has the potential to provide insights for phylogenetic incongruence of Rssc strains based on the host of isolation and may be used to indicate potentially emergent strains.

\footnotetext{
Keywords: Ralstonia solanacearum, microarray, ArrayTube, multiplexing, diagnostic
} 


\section{INTRODUCTION}

Bacterial strains of the Ralstonia solanacearum species complex (Rssc) are considered priority plant pathogens in many countries in the world and are classified as quarantine organisms as well as bioterrorism and double usage agents in the USA and in Europe $(2000 ; 2008)$. Plant protection across borders and territories requires the availability of rapid and reliable protocols to prevent the accidental or intentional introduction of exotic strains. The genetic diversity of Rssc strains is distributed into four major phylotypes and 53 sequevars based on partial sequences of the endoglucanase (egl) gene (Fegan and Prior, 2005). The number of sequevars or lineages can be extended with the discovery of new strains, as demonstrated in sequevars that were identified and characterized in Martinique (French West Indies; Wicker et al., 2009) and Brazil (Albuquerque et al., 2014). A recent polyphasic taxonomic approach based primarily on DNA-DNA hybridizations, Internal transcribed spacer (ITS) and egl partial sequence phylogenetic analyses, and phenotypic data merged the Rssc into three species (Safni et al., 2014): R. solanacearum clustering strains from phylotype II; $R$. pseudosolanacearum clustering strains from phylotypes I and III; and R. syzygii subsp. syzygii comb. nov. clustering strains from phylotype IV, which included two subspecies, $R$. syzygii subsp. celebesensis subsp. nov. and $R$. syzygii subsp. indonesiensis subsp. nov. These data were supported by comparative analyses of whole bacterial genomes (Prior et al., 2016).

Such complexity represents a challenge for any diagnostician attempting to develop protocols and tools to specifically discriminate Rssc strains. Moreover, the ability to identify and distinguish Rssc ecotypes, a group of bacteria sharing the same ecological niche (Cohan, 2002), is important because they represent the most epidemiological active strains in the Rssc causing "famous" diseases, such as potato brown rot or the banana Moko, in valuable agronomic plants. Certain ecotypes can be split into different phylogenetic groups, such as the paraphyletic Moko strains pathogenic to Musaceae and Solanaceae (Cellier et al., 2012; Albuquerque et al., 2014), which have been phylogenetically categorized into sequevars $3,4,6$, $24,25,41$, and 53. Moreover, the difficulty of discriminating among ecotypes increases when high proximity is observed in the genome content of the ecotypes, which has been observed for the pathological variant IIB-4NPB strains (not pathogenic on banana) and Moko sequevar 4 strains (Cellier et al., 2012; Ailloud et al., 2015).

Diagnostic protocols mainly rely on techniques that offer compatible routine application procedures and provide for userfriendly environments, good industrial production capacities, and a high level of reliability. Techniques that primarily employ immunoassays and immune-strip tests (ImmunoStrip ${ }^{\circledR}$; Agdia, Elkhart, IN) are mainly used for the detection of Rssc strains at the species level (Danks and Barker, 2000), and although these assays are simple and affordable, they are known to produce false positives (Narayanasamy, 2010). DNA-based approaches using conventional PCR (Table 1) can identify the Rssc at the species level (Huang and Schell, 1990; Seal et al., 1993; Opina et al.,
1997; Lee and Wang, 2000; Glick et al., 2002; Schonfeld et al., 2003), the phylotype level (Fegan and Prior, 2005); and when these approaches are coupled with sequencing capabilities, they can be used to produce phylogenetic trees (Lane, 1991; Taghavi et al., 1996; Fegan and Prior, 2005; Prior and Fegan, 2005b). General protocols that rely on the evolution of PCR techniques are also available, such as qPCR (Weller et al., 2000; Ozakman and Schaad, 2003; Smith and De Boer, 2009; Inoue and Nakaho, 2014) or LAMP PCR (Lenarcic et al., 2014). Specific protocols have been designed to target a particular group of strains or ecotypes of the Rssc, such as brown rot strains (Fegan et al., 1998; Weller et al., 2000; Ozakman and Schaad, 2003; Smith and De Boer, 2009; Kubota et al., 2011; Ha et al., 2012; Li et al., 2014; Kubota and Jenkins, 2015; Stulberg et al., 2015); Moko strains (Prior and Fegan, 2005a; Cellier et al., 2015); and Blood Disease Bacterium (BDB) strains (Kubota et al., 2011). These diagnostic methods are primarily limited to the detection of strains associated with the brown rot ecotype (Li et al., 2014); however, the Rssc presents a wide diversity of strains.

The main drawback associated with the current methods of detecting and characterizing Rssc strains relies in combining different protocols to properly characterize the strains at their ecotype level. The development of a single method to fully characterize the main groups/ecotypes of the Rssc would greatly benefit the diagnostic field and streamline the workflow for strain identification in an efficient and affordable manner, and it would also facilitate the detection of emerging or unknown strains.

In this study, we employed a multiplex approach to manage the complexity of the Rssc within the framework of microarray technology, which has the potential to test for multiple biomolecular targets in a single reaction. In recent years, applications for the Rssc have been developed for both fundamental (Guidot et al., 2007, 2009; Cellier et al., 2012; Lefeuvre et al., 2013) and applied research (Aittamaa et al., 2008; Pelludat et al., 2009; Dobnik et al., 2014). To provide a costeffective strategy that meets the need for user-friendly processing via conventional lab equipment and high-volume manufacturing capacities that comply with in vitro diagnostic (IVD) regulations, the ArrayTube (AT) platform (Alere Technologies GmbH, Jena, Germany) was selected as the final protocol. This array consists of a custom microarray integrated into a micro reaction vial, which simplifies handling and is used for routing testing in the medical field (Braun et al., 2012; Schneeberg et al., 2015).

Recently, new genomes of the Rssc were fully sequenced and annotated (Ailloud et al., 2015), thus providing new insights for the development of more reliable markers for diagnostic purposes. This paper provides the first description of the production of a microarray (RsscAT) dedicated to characterize strains within 17 major groups of interest in the Rssc with respect to their phylogenetic assignation and ecotype. This portable custom RsscAT provides significant improvements that allow for the rapid assignment of the phylogenetic position of a strain, which can be used to predict the pathogenicity of a strain. RsscAT has the potential to be used for the epidemiological monitoring of heterogeneous Rssc strains worldwide. 
TABLE 1 | List of available PCR tools for the Ralstonia solanacearum species complex diagnostic.

\begin{tabular}{|c|c|c|c|c|c|c|}
\hline PCR names & $\begin{array}{l}\text { Phylogenetic } \\
\text { group }\end{array}$ & Primers name & Target & Primer sequence & bp & $\begin{array}{l}\text { Bibliographic } \\
\text { References }\end{array}$ \\
\hline \multirow{3}{*}{$\begin{array}{l}\text { Phylotypes } \\
\text { Multiplex }\end{array}$} & I & Nmult:21:1F & \multirow[t]{3}{*}{ ITS } & CGTTGATGAGGCGCGCAATTा & 144 & \multirow[t]{3}{*}{ Fegan and Prior, 2005} \\
\hline & III & Nmult:23:AF & & TTACSAGAGCAATCGAAAGATT & 91 & \\
\hline & IV & Nmult:22:InF & & ATTGCCAAGACGAGAGAAGTA & 213 & \\
\hline \multirow[t]{9}{*}{ Moko Multiplex } & \multirow[t]{2}{*}{ Seq 3} & MUS35-F & \multirow[t]{2}{*}{ Uncharacterized } & GCAGTAAAGAAACCCGGTGTT & 401 & \multirow[t]{2}{*}{ Prior and Fegan, 2005a } \\
\hline & & MUS35-R & & TCTGGCGAAAGACGGGATGG & & \\
\hline & \multirow[t]{2}{*}{ Seq 3} & IS24-F & \multirow[t]{2}{*}{ ISRso19 } & TCGGGCGTGAAGAGGCAGAC & 490 & \multirow{2}{*}{$\begin{array}{l}\text { Bagsic-Opulencia et al., } \\
2006\end{array}$} \\
\hline & & IS24-R & & GGAGGTGTGCGCCATCAACTG & & \\
\hline & \multirow[t]{2}{*}{ Seq 4} & MUS20-F & \multirow[t]{2}{*}{ RhiG } & CGGGTGGCTGAGACGAATATC & 351 & \multirow[t]{2}{*}{ Prior and Fegan, 2005a } \\
\hline & & MUS20-R & & GCCTTGTCCAGAATCCGAATG & & \\
\hline & Seq 6 & SI28-R & Uncharacterized & CCCGTGTGACCCCGATAGC & & Prior and Fegan, 2005a \\
\hline & \multirow[t]{2}{*}{ Seq 24} & VC46-F & \multirow[t]{2}{*}{ Uncharacterized } & СTCCTGGGAGTCGGTTGGGTC & 100 & Woo et al., unpublished \\
\hline & & VC46-R & & AGGGAACCTAGGCGTGACTG & & \\
\hline IpxC & Rssc & 759 & IpxC & GTCGCCGTCAACTCACTTTCC & 282 & Opina et al., 1997 \\
\hline & & 760 & & GTCGCCGTCAGCAATGCGGAATCG & & \\
\hline pehA & Rssc & pehA 3 & pehA & CAGCAGAACCCGCGCCTGATCCAG & 480 & Huang and Schell, 1990 \\
\hline & & pehA 6 & & ATCGGACTTGATGCGCAGGCCGTT & & \\
\hline pehB & Rssc & RS3 & pehB & AGCACGACCGGTGCGACCTGCT & 822 & Glick et al., 2002 \\
\hline & & RS4 & & CACCCCGCGCGTGTCGTCGTAG & & \\
\hline flic & Rssc & flic F & fliC & GAACGCCAACGGTGCGAACT & 400 & Schonfeld et al., 2003 \\
\hline & & mutS-RsR.1926 & & GCTGATCACCGGCCCGAACAT & & \\
\hline egl & Rssc & Endo-R & egl & GCGTTGCCCGGCACGAACACC & 800 & Fegan and Prior, 2005 \\
\hline & & Endo-F & & ATGCATGCCGCTGGTCGCCGC & & \\
\hline 16S rRNA & Rssc & $27 \mathrm{~F}$ & $16 S$ & AGAGTTGATMTGGCTCAG & 48 & Taghavi et al., 1996 \\
\hline & & $1492 R$ & & GGTTACCTTGTTACGACTT & & \\
\hline 16S-23S rRNA ITS & Rssc & $1100 \mathrm{~F}$ & ITS & GCAACGAGCGCAACCC & 50 & Lane, 1991 \\
\hline region & & $240 R$ & & TTCGCTCGCCACTACT & & \\
\hline 16S-23S rRNA ITS & Rssc & L1 & ITS & AGTCGTAACAAGGTAGCCG & 48 & Fegan et al., 1998 \\
\hline region & & PS-23Sr & & TACTACGTCCTTCATCG & & \\
\hline Brown rot & Seq1 \& Seq2 & 630 & Genomic DNA fragment & ATACAGAATTCGACCGGCACG & 307 & Fegan et al., 1998 \\
\hline & & 631 & "prophage region" & AATCACATGCAATTCGCCTACG & & \\
\hline IIB-4NPB & IIB-4NPB & $5 \mathrm{~F}$ & Genomic DNA fragment & GCGCGCGAGGCTGGTGATGT & 661 & Cellier et al., 2015 \\
\hline & & $5 \mathrm{R}$ & & TGGGTTCGCAGGCGGACAGC & & \\
\hline Moko & Moko \& NPB & $93 \mathrm{~F}$ & $K f r A$ & CGCTGCGCGGCCGTTCAC & 477 & Cellier et al., 2015 \\
\hline & & $93 R$ & & CGGTCGCGGCATGGGCTT & & \\
\hline BDB & BDB & $121 \mathrm{~F}$ & Uncharacterized & CGTATTGGATGCCGTAATGGA & 344 & Tan, 2003 \\
\hline & & $121 \mathrm{R}$ & & AAGTTCATTGGTGCCGAATCA & & \\
\hline BDB & $\mathrm{BDB}$ & BDB2400-F & GpS & GCTGACTATAGGCACAGCGG & 131 & Kubota et al., 2011 \\
\hline & & BDB2400-R & & AATCGCCGTTCCCATACAAG & & \\
\hline
\end{tabular}




\section{MATERIALS AND METHODS}

\section{Bacterial Strains}

A set of 75 bacterial reference strains (Table 2) was selected to cover the known genetic diversity among Rssc strains. Another set of 12 outgroup strains (Table 2) was used to assess the specificity of each designed probe, It contained strains that are known to be isolated from Solanaceae, Musaceae, soil, water, and strains that are phylogenetically closely related to the Rssc. The bacterial strains were obtained from the Centre de coopération Internationale en Recherche Agronomique pour le Développement (CIRAD-Saint Pierre, Reunion Island), and they were stored at $-80^{\circ} \mathrm{C}$ on cryobeads (Microbank, Prolabs Diagnostics, Toronto, Canada). The bacteria were cultured overnight in Luria-Bertani broth (LB) at $28^{\circ} \mathrm{C}$ with agitation at $250 \mathrm{rpm}$. The Rssc strains were streaked on modified Sequeira semi-selective solid medium containing agar $(18 \mathrm{~g} / \mathrm{L})$, yeast extract $(1 \mathrm{~g} / \mathrm{L})$, peptone $(11 \mathrm{~g} / \mathrm{L})$, glycerol $(6.3 \mathrm{~g} / \mathrm{L})$, crystal violet $(2 \mathrm{mg} / \mathrm{L})$, polymyxin- $\beta$-sulfate $(10 \mathrm{mg} / \mathrm{L})$, tyrothricine $(20 \mathrm{mg} / \mathrm{L})$, chloramphenicol (5 mg/L), 2,3,5-triphenyltetrazolium chloride (11 mg/L), Tilt (Propiconazole; Syngenta, B $\beta$ le, Switzerland; $0.004 \%)$, and penicillin $(20 \mathrm{U})$ and then incubated for $48 \mathrm{~h}$ at $28^{\circ} \mathrm{C}$. The 12 outgroup strains were streaked on LPGA solid medium containing agar $(18 \mathrm{~g} / \mathrm{L})$, yeast extract $(7 \mathrm{~g} / \mathrm{L})$, peptone $(7 \mathrm{~g} / \mathrm{L})$, and glucose $(10 \mathrm{~g} / \mathrm{L})$ and then incubated for $24 \mathrm{~h}$ at $28^{\circ} \mathrm{C}$.

The groups of interest were sorted to resemble the phylogeny of the Rssc (phylotypes, ecotypes) and to reflect epidemic events that have occurred worldwide and that have been reported in the literature. Based on the classification in sequevars, we identified 17 groups (Table 3), including the 4 phylotypes; brown rot strains (sequevars 1 and 2); Moko strains (sequevars 3, 4, 6, and 24), epidemiological variant $4 \mathrm{NPB}$, Grandville wilt strains (sequevar 7); R. syzygii subsp. indoniesensis and R. syzygii subsp. celebensis (BDB).

\section{Probe Design and Selection}

The genomes used to design the probes are freely available on the MicroScope platform (available online at https://www. genoscope.cns.fr/agc/microscope/home/index.php; Vallenet et al., 2009; Genoscope, Evry, France) and the EMBL nucleotide sequence database (Ailloud et al., 2015). A first bioinformatics screening of candidate CDSs was performed using both the comparative genomics tool of the MicroScope platform and a BLAST search against NCBI databases to select CDSs that were conserved in the different phylogenetic subgroups and presented limited or absent identities with DNA sequences from non-target genomes present in the databases. A second bioinformatics selection eliminated the CDSs that were too close to mobile elements (e.g., transposases, integrases, etc.) using a parsing $\mathrm{R}$ (v3.0.0) script (R Development Core Team, 2011). The probes (1-9 per CDS) were designed using two software programs, the Array Oligo Selector (AOS; Bozdech et al., 2003) and OligoArray (OA; Rouillard et al., 2003), according to the following specifications: 50-mer length, 40$70 \%$ GC content, 2 probes per CDS, binding energy ranging between -20 and $-35 \mathrm{kcal} / \mathrm{mol}$ (AOS), Tm $68-88^{\circ} \mathrm{C}(\mathrm{OA})$, exclusion of probes including 20 AT or more (AOS), and exclusion of probes including five consecutive repetitions of one of the four bases (OA). The probes were selected from a file that included all of the previously selected CDSs vs. a file that compiled all of the $R$. solanacearum genomes. A total of 256 candidate probes were generated, and their specificity was verified using a BLAST search against NCBI databases and a specific database that includes Rssc genomes and nontarget genomes (strains genetically close to the Rssc or strains occurring in the same ecological niche (Supplementary Table 1). Primer pairs flanking the candidate probes were designed using Primer 3 (Untergasser et al., 2012), and PCR assays were performed with the selected strains representative of the Rssc diversity (Table 3) to validate the occurrence of the targeted DNA in the different subgroups. Following the PCR screening that removed the candidate DNA regions that were improperly amplified by the target strains, a batch of 100 probes was selected to be implemented and cribbed in the AT technology. This last selection removed probes that yielded unexpected results and generated the final set of 32 validated specific biological probes (Table 4), including a negative control probe that verifies the hybridization process. This set of 32 probes/primers was used to multiplex the 17 groups of interest (RsscAT).

The RsscAT were manufactured by Alere Technologies and consisted of oligonucleotide probes with a $3^{\prime}$ amino modification and C6 spacer. The probes were spotted in duplicate (first batch-AT1) along with other non-specific probes that were not analyzed; and the probes were also spotted in triplicate (second batch-AT2).

\section{Multiplex Linear DNA Amplification and Labeling}

Strains were grown overnight in Luria-Bertani broth (LB) at $28^{\circ} \mathrm{C}$ with agitation at $250 \mathrm{rpm}$, and then mild centrifugation was performed at $5,100 \mathrm{rpm}$ for $10 \mathrm{~min}$ at $10^{\circ} \mathrm{C}$. To prepare the cells for a DNA extraction, the pellets were washed twice with $500 \mu \mathrm{L}$ of $1 \mathrm{M} \mathrm{NaCl}$ solution, centrifuged at 5,100 rpm for $10 \mathrm{~min}$ at $10^{\circ} \mathrm{C}$, and then processed using the Wizard Genomic DNA Purification Kit (Promega, Madison WI, USA) following the manufacturer's instructions.

Following this DNA extraction, a linear PCR amplification was performed in which only one reverse primer was used to linearly amplify each targeted sequence (Table 4). The labeling of the genomic DNA was accomplished during the linear amplification step by using dUTP linked biotin as a marker, which allowed site-specific internal labeling of the corresponding target region, thus leading to the production of single-stranded biotin-labeled products. A total of 25 individual reverse primers were used in a multiplex linear PCR amplification for each Rssc strain. Using the HybridisationPlus Kit (Alere Technologies), $5 \mu \mathrm{L}$ of DNA normalized with $200 \mathrm{ng} / \mu \mathrm{L}$ of genomic DNA were labeled according to the manufacturer's recommendations (3.9 $\mu \mathrm{L}$ Labeling Buffer B1, 0.1 $\mu \mathrm{L}$ Polymerase B2) and $1.35 \mu \mathrm{M}$ of each of the 25 primers. The linear PCR amplification was performed using a Veriti Thermal Cycler (Applied Biosystems, 
TABLE 2 | Ralstonia solanacearum strains and outgroup strains used for validating the RsscAT.

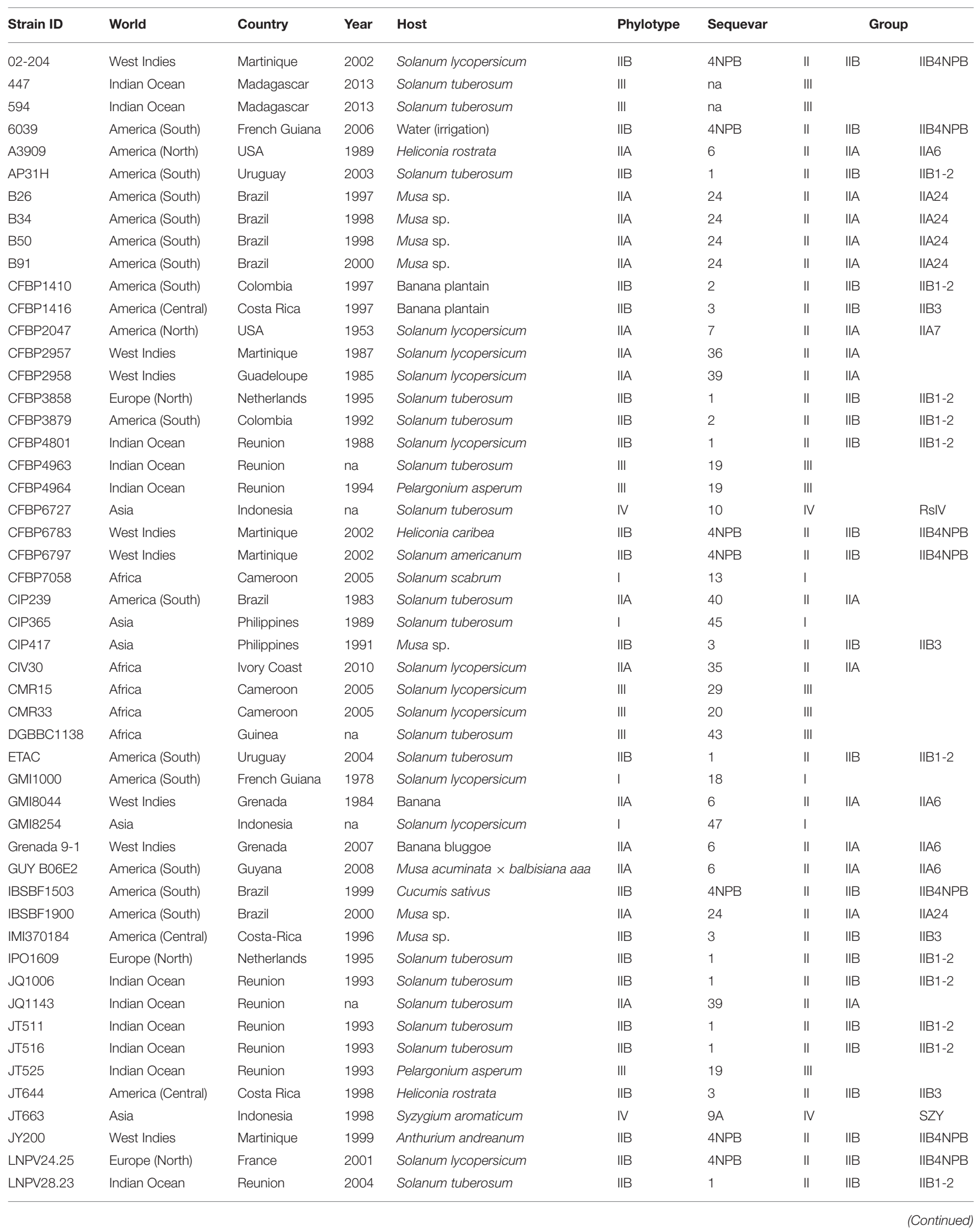


TABLE 2 | Continued

\begin{tabular}{|c|c|c|c|c|c|c|c|c|c|}
\hline \multirow{2}{*}{$\begin{array}{l}\text { Strain ID } \\
\text { MAFF301558 }\end{array}$} & \multirow{2}{*}{$\begin{array}{l}\text { World } \\
\text { Asia }\end{array}$} & \multirow{2}{*}{$\begin{array}{l}\text { Country } \\
\text { Japan }\end{array}$} & \multirow{2}{*}{$\begin{array}{l}\text { Year } \\
2006\end{array}$} & \multirow{2}{*}{$\begin{array}{l}\text { Host } \\
\text { Solanum tuberosum }\end{array}$} & \multirow{2}{*}{$\begin{array}{l}\text { Phylotype } \\
\text { IV }\end{array}$} & \multirow{2}{*}{$\begin{array}{l}\text { Sequevar } \\
8\end{array}$} & \multicolumn{3}{|c|}{ Group } \\
\hline & & & & & & & IV & & RsIV \\
\hline MG144 & Indian Ocean & Madagascar & 2013 & Solanum tuberosum & $\|$ & 1 & $\|$ & IIB & IIB1-2 \\
\hline MG27 & Indian Ocean & Madagascar & 2013 & Solanum tuberosum & III & 19 & III & & \\
\hline MG464 & Indian Ocean & Madagascar & 2013 & Solanum tuberosum & III & 19 & III & & \\
\hline MG49 & Indian Ocean & Madagascar & 2013 & Solanum tuberosum & $\|$ & 1 & $\|$ & $\| \mathrm{B}$ & IIB1-2 \\
\hline MG713 & Indian Ocean & Madagascar & 2013 & Solanum tuberosum & $\|$ & 1 & $\|$ & IIB & IIB1-2 \\
\hline MG732 & Indian Ocean & Madagascar & 2013 & Solanum tuberosum & $\|$ & 1 & $\|$ & IIB & IIB1-2 \\
\hline MG837 & Indian Ocean & Madagascar & 2013 & Solanum tuberosum & $\|$ & 1 & $\|$ & IIB & IIB1-2 \\
\hline MG85 & Indian Ocean & Madagascar & 2013 & Solanum tuberosum & III & na & III & & \\
\hline MOLK2 & Asia & Philippines & 1991 & Musa sp. & $\| \mathrm{B}$ & 3 & $\|$ & IIB & IIB3 \\
\hline NCPPB1018 & Africa & Angola & 1961 & Solanum tuberosum & III & 21 & III & & \\
\hline PSI07 & Asia & Indonesia & na & Solanum lycopersicum & IV & 10 & IV & & RsIV \\
\hline PSS4 & Asia & Taiwan & 1988 & Solanum lycopersicum & 1 & 15 & I & & \\
\hline R229 & Asia & Indonesia & 1988 & Banana & IV & 10 & IV & & $\mathrm{BDB}$ \\
\hline R24 & Asia & Indonesia & na & Syzygium aromaticum & $\mathrm{IVHr}+$ & $9 \mathrm{~B}$ & IV & & SZY \\
\hline R28 & Asia & Indonesia & na & Syzygium aromaticum & IV & 9 & IV & & SZY \\
\hline RF32 & West Indies & Trinidad & 2003 & Solanum lycopersicum & $\| A$ & 7 & $\|$ & $\| A$ & $\| \mathrm{A} 7$ \\
\hline UQRS283 & Asia & Indonesia & na & Solanum lycopersicum & IV & 10 & IV & & RsIV \\
\hline UQRS627 & Asia & Indonesia & 2005 & Musa sp. & IV & 10 & IV & & $\mathrm{BDB}$ \\
\hline UQRS633 & Asia & Indonesia & 2005 & Musa sp. & IV & 10 & IV & & $\mathrm{BDB}$ \\
\hline UW163 & America (South) & Peru & 1967 & Banana plantain & $\| \mathrm{B}$ & 4 & $\|$ & $\| \mathrm{B}$ & IIB4 \\
\hline UW179 & America (South) & Colombia & 1961 & Banana plantain & $\| \mathrm{B}$ & 4 & $\|$ & $\| \mathrm{B}$ & IIB4 \\
\hline UW181 & America (South) & Venezuela & 1960 & Banana plantain & $\| A$ & 6 & $\|$ & $\| A$ & $\| A 6$ \\
\hline UW551 & Africa & Kenya & 2003 & Pelargonium asperum & $\| \mathrm{B}$ & 1 & $\|$ & IIB & IIB1-2 \\
\hline CFBP7122 & Africa & Ethiopia & 1995 & Musa sp. & Xanthomona & vasicola pv. I & 40 & & \\
\hline LMG0911 & Oceania & New Zealand & 1957 & Solanum lycopersicum & Xanthomona & vesicatoria & & & \\
\hline LMG1199 & America (North) & USA & 1957 & Soil & Cupriavidus & cator & & & \\
\hline LMG16206 & na & na & 1995 & na & Pseudomon & putida & & & \\
\hline LMG1794 & Europe (North) & United Kingdom & 1951 & Water (irrigation) & Pseudomon & fluorescens & & & \\
\hline LMG2172 & Europe (North) & United Kingdom & 1972 & Solanum lycopersicum & Pseudomon & corrugata & & & \\
\hline LMG2804 & America (North) & USA & 1956 & Chrysanthemum morifolium & Dickeya chry & anthemi bv. c & sant & & \\
\hline LMG2894 & Europe (North) & Sweden & 1956 & Solanum tuberosum & Clavibacter $n$ & chiganensis & sp. s & donicus & \\
\hline LMG5093 & Europe (North) & United Kingdom & 1960 & Solanum lycopersicum & Pseudomon & syringae pv. & nato & & \\
\hline LMG5942 & America (North) & USA & 1974 & Human & Ralstonia pic & ettii & & & \\
\hline LMG7333 & Europe (North) & Hungary & 1957 & Solanum lycopersicum & Clavibacter $n$ & chiganensis & sp. $n$ & iganensis & \\
\hline NCPPB2968 & America (North) & USA & 1977 & Capsicum frutescens & Xanthomona & axonopodis & resic & & \\
\hline
\end{tabular}

Carlsbad, CA, USA) with the following parameters: $5 \mathrm{~min}$ at $96^{\circ} \mathrm{C}$; followed by 45 cycles of $60^{\circ} \mathrm{C}$ for $20 \mathrm{~s}, 72^{\circ} \mathrm{C}$ for $30 \mathrm{~s}$, and $96^{\circ} \mathrm{C}$ for $20 \mathrm{~s}$; and a final hold at $4^{\circ} \mathrm{C}$.

\section{Microarray Hybridization and Data Acquisition}

The reagents required for the hybridization steps were provided by the HybridisationPlus Kit (Alere Technologies), and the protocols were performed according to the manufacturer's recommendations except for certain conditions that were optimized according to the probe design requirements.

The prewashing steps of the RsscAT consisted of adding $500 \mu \mathrm{L}$ of $60^{\circ} \mathrm{C}$ preheated ultrapure water for a $5 \mathrm{~min}$ incubation at $60^{\circ} \mathrm{C}$ and stirring at $550 \mathrm{rpm}$. The flow was discarded, and then $200 \mu \mathrm{L}$ of hybridization buffer $\mathrm{C} 1$ preheated at $60^{\circ} \mathrm{C}$ was added and incubated for $2 \mathrm{~min}$ at $60^{\circ} \mathrm{C}$ with stirring at $550 \mathrm{rpm}$. The flow was discarded, and then 100 $\mu \mathrm{L}$ of hybridization mix consisting of $10 \mu \mathrm{L}$ of labeled DNA and $90 \mu \mathrm{L}$ of the hybridization buffer (C1) preheated at $60^{\circ} \mathrm{C}$ was transferred into a prewashed RsscAT and then incubated for $1 \mathrm{~h}$ incubation at $60^{\circ} \mathrm{C}$ with stirring at 550 rpm.

The washing steps consisted of heating the hybridized RsscAT at $42^{\circ} \mathrm{C}$ and discarding the hybridization mix, and then 500 $\mu \mathrm{L}$ of preheated washing buffer 1 (C2) at $42^{\circ} \mathrm{C}$ was added and incubated for $5 \mathrm{~min}$ at $42^{\circ} \mathrm{C}$ with stirring at $550 \mathrm{rpm}$. The flow was then discarded, and these steps were repeated two more times, with the last repetition performed at $30^{\circ} \mathrm{C}$. 
TABLE 3 | The 17 groups of interest of the Ralstonia solanacearum species complex.

\begin{tabular}{|c|c|c|c|c|}
\hline Group of interest & Phylotype & Sequevars & Common name & nb Hyb strains ${ }^{c}$ \\
\hline GC & All & All known sequevars 1-53 & Rssc & 128 \\
\hline I & 1 & $\begin{array}{l}\text { All Phylotype I sequevars: } \\
12 ; 13 ; 14 ; 15 ; 16 ; 17 ; 18 ; 31 ; 34 ; 44 ; 45 ; 46 ; 47 ; 48\end{array}$ & & 7 \\
\hline ॥ & $\|$ & $\begin{array}{l}\text { All Phylotype II sequevars: } \\
1 ; 2 ; 3 ; 4 ; 4 \mathrm{NPB} ; 5 ; 6 ; 7 ; 24 ; 25 ; 26 ; 27 ; 28 ; 28 ; 35 ; 36 ; 37 ; 38 ; 39 ; 40 ; 41 ; \\
50 ; 51 ; 52 ; 53\end{array}$ & & 80 \\
\hline$\| \mathrm{A}$ & $\| A$ & $\begin{array}{l}\text { All Phylotype IIA sequevars: } \\
5 ; 6 ; 7 ; 24 ; 28 ; 35 ; 36 ; 37 ; 38 ; 39 ; 40 ; 41 ; 50 ; 52 ; 53\end{array}$ & & 30 \\
\hline IIA6 & $\| A$ & 6 & Moko & 9 \\
\hline$\| \mathrm{A} 7$ & $\| A$ & 7 & Grandville wilt & 7 \\
\hline IIA24 & $\| A$ & 24 & Moko & 7 \\
\hline IIB & IIB & All Phylotype IIB sequevars: 1;2;3;4;4NPB;25;26;27;28;51 & & 50 \\
\hline IIB1-2 & $\| \mathrm{B}$ & $1 ; 2$ & Brown rot & 24 \\
\hline IIB3 & $\| \mathrm{B}$ & 3 & Moko & 10 \\
\hline IIB4 & $\| \mathrm{B}$ & 4 & Moko & 4 \\
\hline IIB4NPB & $\| \mathrm{B}$ & 4NPB & Epidemiological variant 4NPB & 11 \\
\hline III & III & All Phylotype III sequevars: 19;20;21;22;23;29;42;43;49 & & 14 \\
\hline IV & IV & All Phylotype IV sequevars: 8;9;10;11 & & 15 \\
\hline RsIV & IV & $8 ; 9^{\mathrm{a}} ; 10^{\mathrm{a}}, 11$ & & 5 \\
\hline BDB & IV & 10 & R. syzigii subsp. Celebensis & 5 \\
\hline SZY & IV & $9^{b}$ & R. syzigii subsp. indoniensis & 5 \\
\hline
\end{tabular}

a Only R. solanacearum strains.

${ }^{b}$ Only SZY strains in seq 9.

${ }^{c}$ Number of hybridized strains used for validating each group of interest on the RsscAT.

The conjugate mix, which consisted of $1 \mu \mathrm{L}$ of preheated HRP conjugate $100 \mathrm{x}(\mathrm{C} 3)$ and $99 \mu \mathrm{L}$ of preheated conjugate buffer (C4) at $30^{\circ} \mathrm{C}$, was added to the washed RsscAT and then incubated for $10 \mathrm{~min}$ at $30^{\circ} \mathrm{C}$ with stirring at $550 \mathrm{rpm}$. Another washing step consisted of discarding the flow, adding $500 \mu \mathrm{L}$ of washing buffer 2 (C5), and then incubating for $5 \mathrm{~min}$ at $30^{\circ} \mathrm{C}$ with stirring at $550 \mathrm{rpm}$. The final coloration step consisted of discarding the flow, adding $100 \mu \mathrm{L}$ of HRP substrate buffer (D1) that was already acclimated to room temperature, and incubating for $5 \mathrm{~min}$ at $30^{\circ} \mathrm{C}$ without stirring.

Data acquisition was performed with the software provided with the ATR03 scanner (Alere Technologies) following the manufacturer's instructions.

\section{Data Analysis}

Hybridization signals were processed using the IconoClust software version 3.3, and all of the spots were automatically normalized by the software according to the equation $N I=1-(M / B G)$, where $N I$ is the normalized intensity, $M$ is the average intensity of the automatically recognized spot, and $B G$ is the intensity of the local background. The output range of the signals was between 0 and 1 , with 0 being negative and 1 being the maximal possible signal value. These raw data were processed using a home-made $\mathrm{R}$ script (provided upon request) that could set a threshold to discriminate positive probe signals from negative probe signals. The threshold was manually assigned to 0.6 , which allowed for clear discrimination of positive and negative signals. The threshold for the control probe GC_07 (Rssc strains) was set to 0.4. Signals with intensities higher than the assigned threshold were considered positive and set as "1." Signals lower than the assigned threshold were regarded as negative and set as " 0. "

\section{Statistics}

Different replicates were performed to assess the repeatability of the protocol. Each probe was spotted in duplicate (batch AT1) or triplicate (batch AT2) to evaluate the intra-assay repeatability, which was calculated based on the consistency rate within each batch or for both batches. Several strains (2 for batch AT1 and 6 for batch AT2) were tested twice or three times in the same batch to evaluate the inter-assay repeatability, which was calculated based on the proportion of consistent results among the different hybridization repeats.

Twenty-seven strains were tested in both the AT1 and AT2 batches. For these strains, the relative specificity, $S P=\frac{T N}{T N+F P}$; the relative sensitivity, $S E=\frac{T P}{T P+F N}$; and the Diagnostic Odds Ratio, $D O R=\frac{T P / F P}{F N / T N}$ and the corresponding 95\% confidence interval $(95 \% \mathrm{CI})$, were calculated for each batch, where TP, FP, $\mathrm{FN}$, and TN refer to true positive, false positive, false negative and true negative, respectively. The DOR value ranged from 0 to infinity, with higher values indicating better discriminatory test performance. The DOR values were compared between the two batches using the Breslow-Day test of the Homogeneity of Odds Ratios $(p=0.05)$. 
$\stackrel{\infty}{\sim} \wedge$ வ
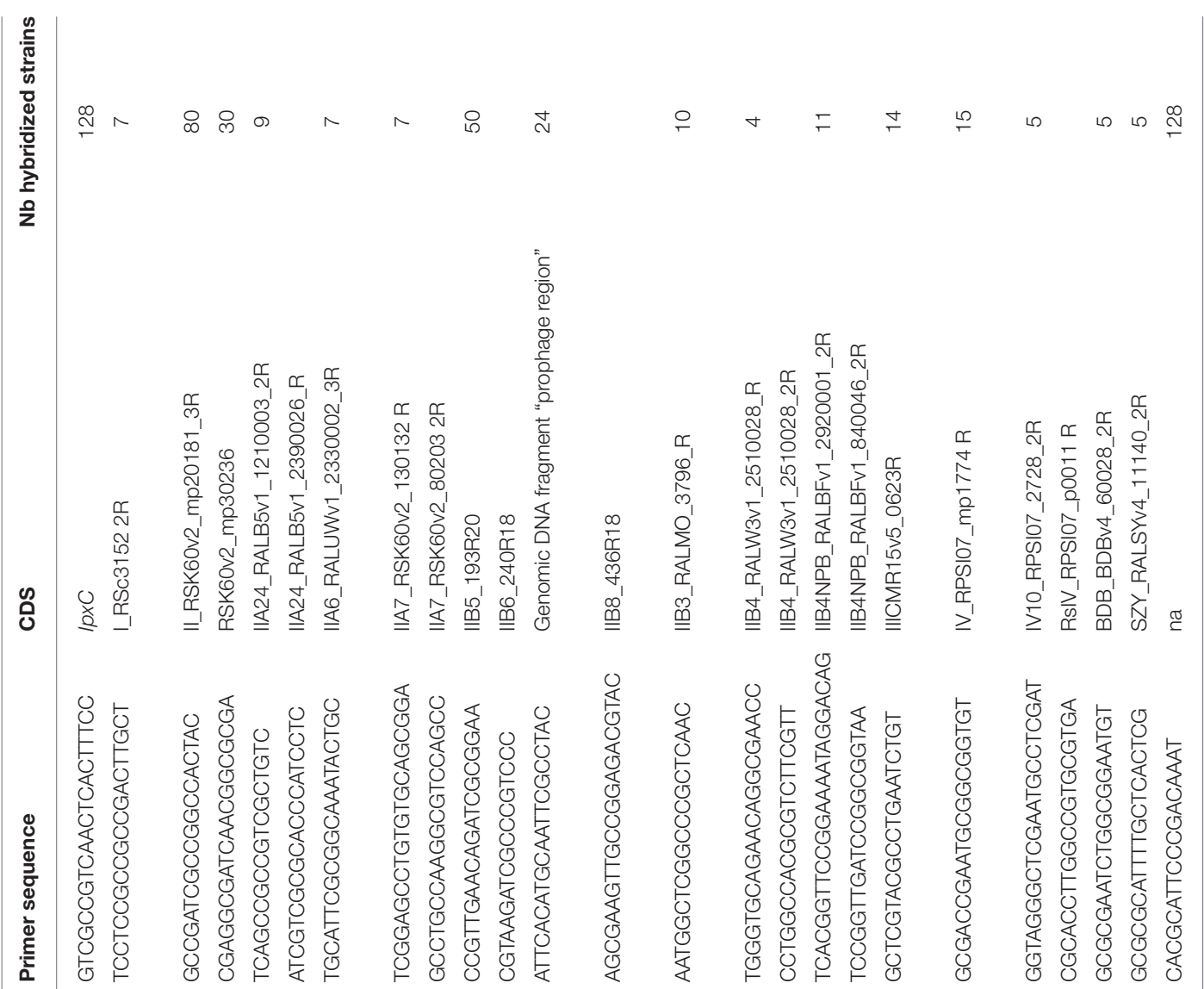

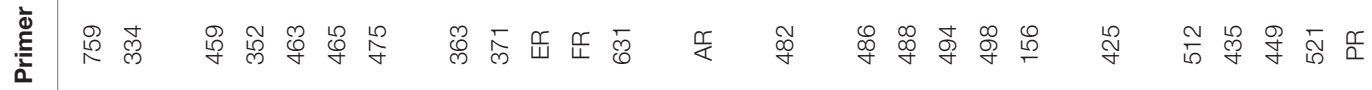

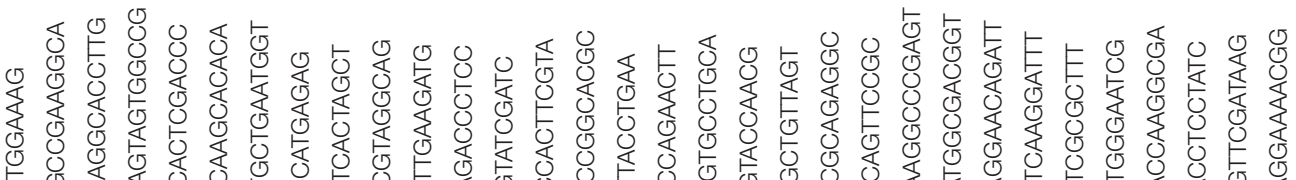

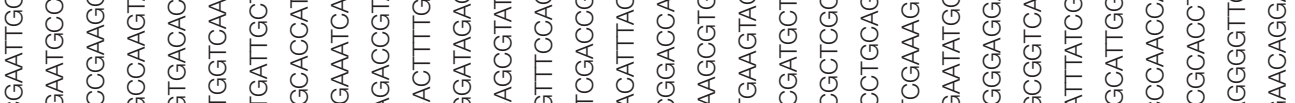

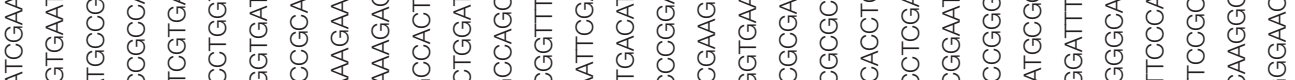

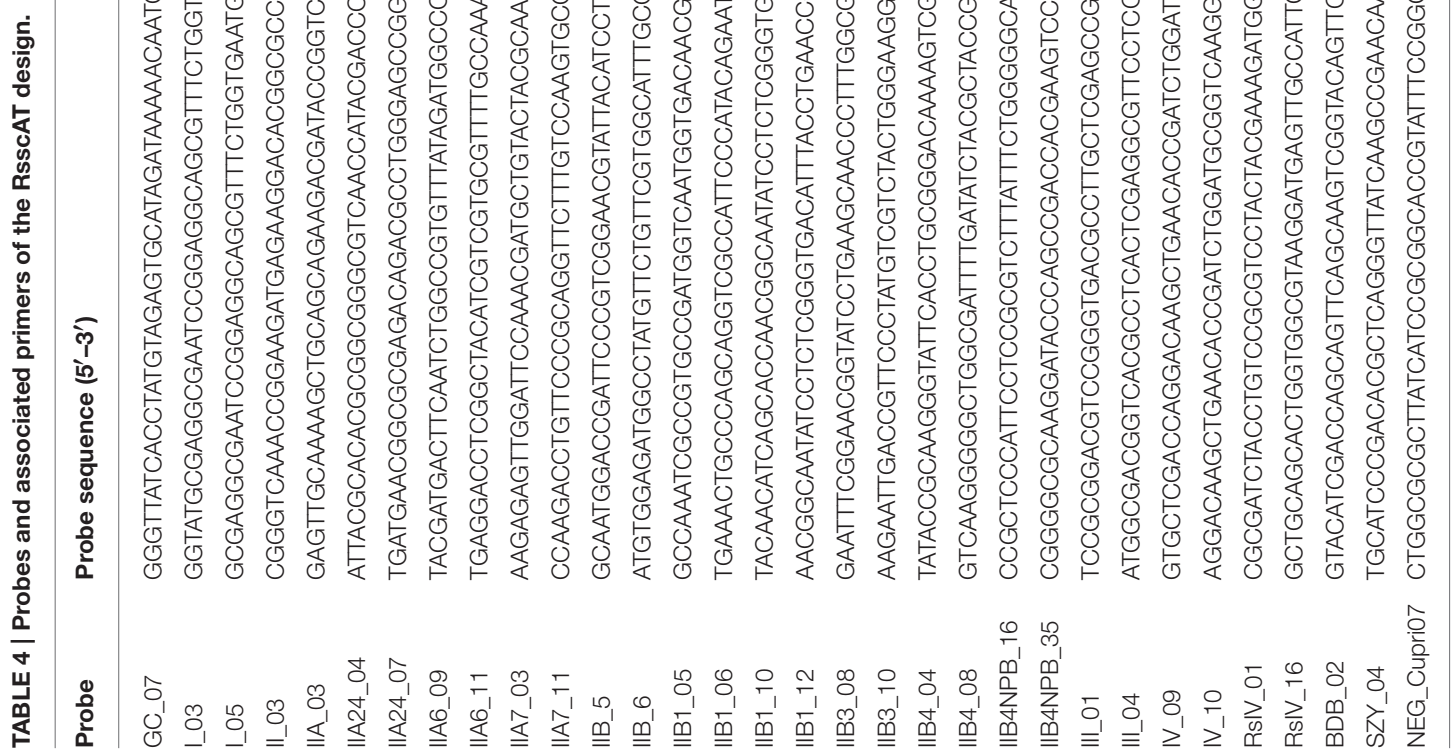


Finally, the SP and SE were calculated for each group of interest using the data acquired for the 75 target strains and the 12 outgroups in the two batches.

\section{RESULTS AND DISCUSSION}

The RsscAT was developed to evaluate diverse bacterial strains and represents an affordable, accurate, fast, and user-friendly diagnostic tool with a high potential for standardization and routine diagnostic testing use. Microarrays developed using the conventional glass slide format with fluorescence detection (e.g., Cy3/Cy5) have a high operational burden because of the high laboratory skill required to handle the material and perform the bioinformatics computations, as well as the high cost of the equipment. Although high-density microarrays are more likely to meet research laboratory expectations, routine laboratory diagnostics require more user-friendly and efficient protocols. AT format microarrays provide a valuable option for diagnosticians who need to efficiently test a large number of markers at the same time. The ability of the AT microarray to identify and discriminate strains of the Rssc was evaluated using a set of 75 target strains representing the 17 main groups of the Rssc and 12 outgroup strains that are found in the same environment and show a high likelihood of interfering with the identification of Rssc strains (pathogenic or saprophytic strains).

\section{Probe Design}

The first step in developing the RsscAT was to design accurate probes specific to the 17 phylogenetic groups of the Rssc. This design step was performed in several stages during which our strong focus on achieving the specificity of the selected templates (CDS or probes) was maintained via in silico analyses and experimental data.

Probes were designed with a 50-mer length constraint, which provided sufficient length for a probe that balances specificity and flexibility and is capable of identifying the best sequences markers (Palmer et al., 2006).

The probability of secondary structures (e.g., hairpins) was checked during the probe design and used to select candidate probes and then enhance the probe signals. Additionally, the use of single-stranded DNA as a template prevented competition between the probe and antisense strand and increased the probability of single-stranded DNA hybridization to the probe.

To our knowledge, we have designed the first probe set that can characterize Rssc ecotypes and strains regardless of the array technology, including macroarrays, microarrays, glass slides, nylon, or AT. Although various strain typing designs used in the medical field provide detection at levels below the species level (Schmoock et al., 2011; Braun et al., 2012), most of the designs available for Rssc strains have focused on detection at the species level (Aittamaa et al., 2008; Pelludat et al., 2009; Dobnik et al., 2014); moreover, these designs are constrained by the sensitivity of the tests, which is a drawback of array technology. Here, RsccAT was presented as a characterization protocol, and it can be integrated at the second step of strain identification after the steps for isolating and detecting the target Rssc strain (by ELISA, PCR, etc.). Therefore, the sensitivity constraint is not applicable because a significant amount of DNA can be extracted from the pure culture strains.

\section{Control Responses}

The internal positive controls from Alere Technologies generated the expected positive results, and the negative control probe NEG_Cupri07 generated the expected negative results for each hybridization. The control probe GC_07 for the Rssc strains generated the expected results for most of the strains; however, the following 4 phylotype III strains showed a lower intensity signal: 447, 594, MG464 (Madagascar), and CFBP4964 (Reunion). This result suggested the presence of mismatches between the probe and the amplified targets. Because a signal was observed between the expected positive and expected negative strains, we lowered the threshold for this specific probe to 0.4. Using this threshold, all of the strains of the Rssc tested positive (100\% inclusivity). This last result was expected because the probe GC_07 is included in the UDP-3-O-acyl-GlcNAc deacetylase $(\mathrm{lpxC})$ gene, which has been successfully used in the design and validation of specific primers for the Rssc (Opina et al., 1997; Villa et al., 2003; Fegan and Prior, 2005). Additionally, the 12 outgroup strains did not hybridize on any of the 32 developed probes except the $R$. pickettii strain LMG5942, which was detected by the probes III_04 and BDB_02 (83.3\% exclusivity). Nevertheless, this false positive data was not considered because the $R$. solanacearum positive control probe GC_07 did not test positive for this strain. The results obtained with the control probes confirmed the reliability of the hybridization step and supported the high specificity of the RsscAT.

No significant results were observed between the odds ratios for the batches (Breslow-Day test, $p=0.4375$ ), which indicated that the different strains presented globally similar responses when the two batches were tested; however, the common probes of the two arrays were spotted under different conditions for these two batches (different locations and repetitions), which indicates the high reproducibility of this AT microarray protocol.

The ability of the AT microarray to identify and discriminate strains of the Rssc was evaluated using a set of 75 target strains representing the 17 main groups of the Rssc and 12 outgroup strains that are found in the same environment and show a high likelihood of interfering with the identification of Rssc strains (pathogenic or saprophytic strains).

\section{Phylotype Identification}

High relative specificity of $98.07 \%$ (95\% CI 96.65-99) and sensitivity values of $100 \%$ (95\% CI 90.26-100) were obtained for both probes that typed phylotype I. Indeed, the probes designed to detect phylotype I yielded the expected specific positive results for all of the tested strains of phylotype I, and they only yielded a false positive signal for the strains CFBP1418 (IIB-4NPB) and JT663 (SZY).

Moreover, a relative specificity of $100 \%$ (95\% CI $97.20-$ 100) was obtained for all of the probes typing phylotype II. However, the relative sensitivity value $(67.61-95 \%$ CI 60.87-73.84) indicated that these probes presented issues with inclusivity. The phylotype II probes could not accurately detect 
the Moko IIB-3 strains, IIB-4 strains, IB-4NPB strains and certain IIA strains (CIP239 and JQ1143). One of the repetitions did yield a positive signal for IBSBF1503 (IIB-4NPB), LNPV24.25 (IIB-4NPB), and MolK2 (IIB-3); however, full specificity was not observed.

However, high relative specificity and sensitivity values were obtained for the probes that detected phylotypes IIA and IIB, with 99.24\% (95\% CI 97.27-99.91) and 100\% (95\% CI 99.12-100) relative specificity for phylotypes IIA and IIB, respectively, and 94.94\% (95\% CI 87.54-98.60) and 97.81\% (95\% CI 95.29-99.19) relative sensitivity for phylotypes IIA and IIB, respectively. Thus, the target strains for phylotypes IIA and IIB were successfully detected except for strain CIP239 belonging to IIA-40.

All the strains from phylotype III were successfully detected by the two dedicated probes, and a $100 \%$ relative sensitivity value (95\% CI 95.49-100) was observed. A high relative specificity value of $99.49 \%$ (95\% CI 98.51-99.89) was also obtained, and false positive signals were only registered for probe III_04 when testing LMG 5942 (see Section Controls).

All of the phylotype IV target strains except strain JT663 were detected, and false positive values were not registered, thereby resulting in a $100 \%$ relative specificity value $(95 \%$ CI $99.38-$ $100)$ and a high relative sensitivity value of $93.67 \%$ (95\% CI 85.84-97.91).

To conclude, the specific probes yielded the expected results and showed good specificity. The only group that showed lower reliability was the phylotype II probes, which did not yield true positive signals for the Moko IIB strains and epidemiological IIB-4NPB strains. The phylogenetic and genomic characteristics of the Moko IIB-4 strains and IIB4NPB strains are closely correlated (Ailloud et al., 2015), whereas these characteristics of the Moko IIB-3 strains are less correlated. The lack of sensitivity of the phylotype II probes for this particular group of strains was not predicted by the computer analysis or PCR amplification of the target. Nevertheless, the results obtained with the probes targeting the two subgroups IIA and IIB inside phylotype II largely overcame the inclusivity problems shown with the phylotype II probes.

\section{Ecotype and Lineage Identification}

The ecotype of the Rssc strains (e.g., brown rot, Moko, NPB, $\mathrm{BDB}$, and RSY) is the lowest level of genetic diversity that can be detected with the RsscAT, and an accurate ecotype analysis must be performed with additional groups of probes. Hence, a hierarchical analysis of the probe groups must be performed to develop an accurate characterization of the target strain. Once the status of the Rssc strain is validated, the phylotype can be determined and then, if possible, the ecotype is also determined accordingly to a particular ecotype. This process can circumvent the interpretation of false negative/positive signals.

The results (Table 5) showed that the Grandville wilt ecotype from phylotype IIA-7, the epidemiological variant IIB-4NPB, and the $\mathrm{BDB}$ ecotype were fully and specifically detected.

Brown rot strains were fully characterized by the dedicated specific probes by considering the complementary responses displayed by the four probes. Indeed, false negative responses

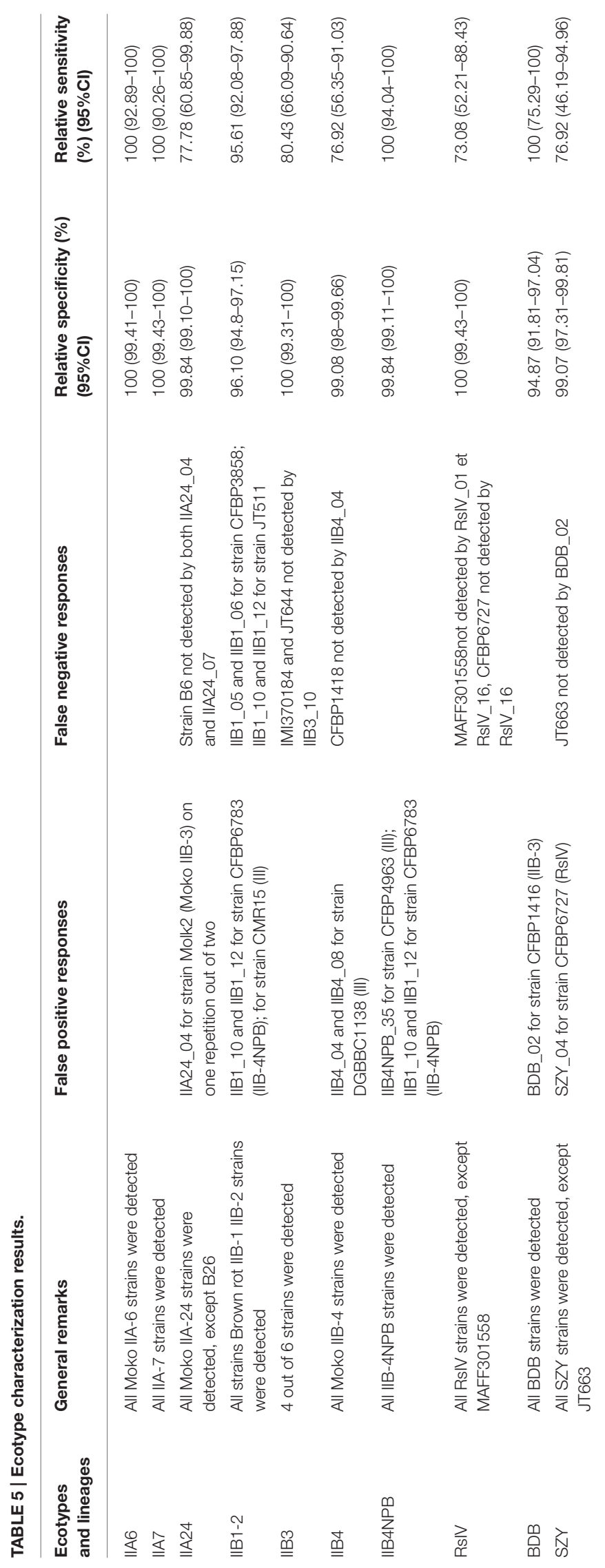


obtained for the probes IIB1_05 and IIB1_06 were overcome by the IIB1_10 and IIB1_12 responses and vice versa. This result highlighted the importance to have several probes for a given group of interest, located if possible on different CDS, which was the case for the Brown-rot strains-targeting probes. Interestingly, the IIB1_10 and IIB1_12 probes matched with a specific genome region selected with a different in silico approach and used to develop a Brown rot strains specific real-time quantitative PCR assay (Stulberg and Huang, 2015).

The paraphyletic Moko strains are sorted into different clusters within phylotype II (IA-6, IIA-24, IIB-3, and IIB-4), which highlights the genomic complexity and heterogeneity of this ecotype. Although these strains are epidemiologically adapted to wilt Musaceae, these strains also show pathogenicity to Solanaceae in controlled conditions (Cellier and Prior, 2010). Moko sequevars 4 and 6 were specifically detected, whereas sequevars 3 and 24 showed false negative signals despite the amplification of the respective target sequences by PCR. The hybridization process between the probe and the amplified DNA from these three strains might have been compromised by substitution of the DNA sequence, thereby leading to false negative signals. The hybridization parameters have been fully discussed in Tomlinson et al. (2014). Several site substitutions at specific regions of the amplified DNA can lead to a significant decrease in the positive signal, and the same false negative characterization at the ecotype level was observed for strain JT663 in the SZY ecotype and MAFF301558 in the RsIV ecotype. Complementary specific PCRs could be used when information at the ecotype level is lacking (Table 1).

Several false negative signals were obtained for some ecotypes; however, as previously noted, a hierarchical analysis of the probe groups could help to resolve such strain assignments. For example, strain CMR15 has been typed on AT as an IIB-1 strain by the IIB1_06 probe; however, this strain has been identified as a phylotype III strain and could not be an IIB-1 strain.

Additionally, strain CFBP6783 has been identified as a probable IIB-1 strain; however, it belongs to the IIB-4NPB group. Nevertheless, this result is not reliable (non-homogeneous repetitions of two IIB-1 probes and no identification by the two other IIB-1 probes) because all IIB-4NPB probes indicate that this strain is actually an IIB-4NPB strain.

\section{Intra-Repeatability, Inter-Repeatability, and Reproducibility}

A consistency rate of $99.65 \%$ was obtained for the duplicate spotted probes for the AT1 batch and $99.97 \%$ was obtained for the triplicate spotted probes in the AT2 batch; thus, the RsscAT method showed a high degree of intra-array repeatability. In addition, high inter-array repeatability values were also observed, with consistency rates of $97.06 \%$ (batch AT1) and 99.51\% (batch AT2). For the set of 27 strains analyzed from both batches (AT1 \& AT2), the major indicators of diagnostic test performance presented high values. Thus, the relative specificity, relative sensitivity, odds ratios and the corresponding 95\% confidence intervals were $98.81 \%$ (95\% CI 98.16-99.27), 96.07\% (95\% CI 93.08-98.02), and 1976.8 (95\% CI 914.8 4300.3), respectively, when the strains were hybridized on batch AT1; and $98.81 \%(95 \%$ CI 98.36-99.17), 94.47\% (95\% CI 92.25-96.21), and 1371.37 (95\% CI 869.92-2474.9), respectively, when the strains were hybridized on batch AT2.

No significant results were observed between the odds ratios for the batches (Breslow-Day test, $p=0.4375$ ), which indicated that the different strains presented globally similar responses when the two batches were tested; however, the common probes of the two arrays were spotted under different conditions for these two batches (different locations and repetitions), which indicates the high reproducibility of this AT microarray protocol.

\section{CONCLUSION}

The design presented here is highly reliable, and the repetitions of probes as well as the different levels of characterization were able to differentiate among the target strains within the 17 different groups of high importance within the Rssc. This design is also able to detect phylogenetic incongruence among strains according to the host isolation, and then can also detect emergent strains that will require further confirmation tests. Different outcomes and scenarios could emerge from this RsccAT analysis: for example, strains characterized as Moko on tomato (Solanum lycopersicum) represent serious cases and require immediate action; however, tests that rely on species-level analyses would give the positive result for the detection of " $R$. solanacearum" strains and a negative result for the specific detection of brown rot strains. Additionally, the ecotype level represents strain groups that are epidemiologically active worldwide; hence, the strains identified at the phylotype level but not at the ecotype level represent anomalies that require further investigation.

Currently, only limited eradication and containment strategies are available to control Rssc strains once they have been introduced into a territory. Hence, preventing such introductions and developing tools to identify and characterize the quarantined organisms remain priorities for the agricultural industry. The developed RsscAT dedicated to identifying Rssc strains was designed to minimize time and costs and maximize marker multiplexing and reliability, and it is only applied on pure culture strains. Multiplexing the markers into a compact, affordable, and user-friendly technology for infra-species-level characterizations of Rssc strains is the goal of the RsccAT design. A total of 17 groups can be interpreted in a phylogenetic hierarchical fashion that covers the main phylogenetic groups and ecotypes of the Rssc. Although ELISA, conventional or real time PCR, LAMP-PCR, and other molecular tools are designed to test for a multitude of strains in one reaction based on one or very few markers, the RsscAT is design to test for a multitude of markers in one reaction for one strain. This profile makes the RsscAT as a strong complementary diagnostic protocol within a diagnostic scheme. The RsscAT diagnostic array presents a number of benefits, such as an industry-standard format and a high level of reliability, and it also provides diagnostic laboratories with a user-friendly, cost-efficient and time-efficient option that can be used for epidemiological monitoring of Rssc strains. 


\section{AUTHOR CONTRIBUTIONS}

Conceived and designed the experiments: GC, IR, PP. Performed the experiments: GC, SA. Analyzed the data: GC, IR, SA, FC. Contributed reagents/materials/analysis tools: GC, IR, PP. Wrote the paper: GC, IR, PP.

\section{FUNDING}

This research was funded by the European Union (POSEIDOM phytosanitaire, 2011/132/UE, 2012/182/UE, 2013/175/UE, C(2014)8353), the Conseil Régional de La Réunion, the French National Research Institutes ANSES, INRA, and CIRAD.

\section{REFERENCES}

(2000). European Commision (2000) Council Directive 2000/29/EC Concerning Protective Measures against the Introduction into the Community of Organisms Harmful to Plants or Plant Products and against Their Spread within the Community. Official Journal L169. Council Directive 2000/29/EC.

(2008). Possession, Use, and Transfer of Select Agents and Toxins. Final rule. Federal Register, 73.

Ailloud, F., Lowe, T., Cellier, G., Roche, D., Allen, C., and Prior, P. (2015). Comparative genomic analysis of Ralstonia solanacearum reveals candidate genes for host specificity. BMC Genomics 16:270. doi: 10.1186/s12864-015-1474-8

Aittamaa, M., Somervuo, P., Pirhonen, M., Mattinen, L., Nissinen, R., Auvinen, P., et al. (2008). Distinguishing bacterial pathogens of potato using a genome-wide microarray approach. Mol. Plant Pathol. 9, 705-717. doi: 10.1111/j.1364-3703.2008.00482.x

Albuquerque, G. M., Santos, L. A., Felix, K. C., Rollemberg, C. L., Silva, A. M., Souza, E. B., et al. (2014). Moko disease-causing strains of Ralstonia solanacearum from Brazil extend known diversity in paraphyletic phylotype II. Phytopathology 104, 1175-1182. doi: 10.1094/PHYTO-12-13-0334-R

Bagsic-Opulencia, R., Raymundo, A. K., and Fegan, M. (2006). "Development of a PCR-based molecular diagnostic test for R. solanacearum Phylotype II Sequevar 3 strains causing bacterial wilt of banana," in The 4th International Bacterial Wilt Symposium, Centre, Central Science Laboratory, York.

Bozdech, Z., Zhu, J., Joachimiak, M. P., Cohen, F. E., Pulliam, B., and DeRisi, J. L. (2003). Expression profiling of the schizont and trophozoite stages of Plasmodium falciparum with a long-oligonucleotide microarray. Genome Biol. 4:R9. doi: 10.1186/gb-2003-4-2-r9

Braun, S. D., Ziegler, A., Methner, U., Slickers, P., Keiling, S., Monecke, S., et al. (2012). Fast DNA serotyping and antimicrobial resistance gene determination of Salmonella enterica with an oligonucleotide microarray-based assay. PLoS ONE 7:e46489. doi: 10.1371/journal.pone.0046489

Cellier, G., and Prior, P. (2010). Deciphering phenotypic diversity of Ralstonia solanacearum strains pathogenic to potato. Phytopathology 100, 1250-1261. doi: 10.1094/PHYTO-02-10-0059

Cellier, G., Remenant, B., Chiroleu, F., Lefeuvre, P., and Prior, P. (2012). Phylogeny and population structure of brown rot- and Moko disease-causing strains of Ralstonia solanacearum phylotype II. Appl. Environ. Microbiol. 78, 2367-2375. doi: 10.1128/AEM.06123-11

Cellier, G., Moreau, A., Chabirand, A., Hostachy, B., Ailloud, F., and Prior, P. (2015). A duplex PCR assay for the detection of Ralstonia solanacearum Phylotype II strains in Musa spp. PLoS ONE 10:e0122182. doi: 10.1371/journal.pone.0122182

Cohan, F. M. (2002). What are bacterial species? Annu. Rev. Microbiol. 56, 457-487. doi: 10.1146/annurev.micro.56.012302.160634

Danks, C., and Barker, I. (2000). On-site detection of plant pathogens using lateral-flow devices. EPPO Bull. 30, 421-426. doi: 10.1111/j.1365-2338.2000. tb00922.x

\section{ACKNOWLEDGMENTS}

We thank Jessica Barthet, Audrey Farbos, and Pierre Grygiel for their expert technical assistance in microarray handling; JeanJacques Chéron for his professional advice and expert technical assistance in microbiology, and Pierre Lefeuvre and Florent Ailloud for their expert technical assistance in bioinformatics analyses.

\section{SUPPLEMENTARY MATERIAL}

The Supplementary Material for this article can be found online at: http://journal.frontiersin.org/article/10.3389/fpls.2017. 00821/full\#supplementary-material

Dobnik, D., Morisset, D., Lenarcic, R., and Ravnikar, M. (2014). Simultaneous detection of RNA and DNA targets based on multiplex isothermal amplification. J. Agric. Food Chem. 62, 2989-2996. doi: 10.1021/jf5002149

Fegan, M., and Prior, P. (2005). "How complex is the Ralstonia solanacearum species complex," in Bacterial Wilt Disease and the Ralstonia solanacearum Species Complex, eds C. Allen, P. Prior, and A. C. Hayward (St. Paul: APS Press), 449-461.

Fegan, M., Hollway, G., Hayward, A. C., and Timmis, J. (1998). "Development of a diagnostic test based upon the polymerase chain reaction (PCR) to identify strains of Ralstonia solanacearum exhibiting the biovar 2 genotype," in Bacterial Wilt Disease Molecular and Ecological Aspects, eds P. Prior, C. Allen, and J. Elphinstone (Paris: INRA Editions), 34-43.

Glick, D. L., Coffey, C. M., and Sulzinski, M. A. (2002). Simultaneous PCR detection of the two major bacterial pathogens of geranium. J. Phytopathol. 150, 54-59. doi: 10.1046/j.1439-0434.20 02.00716.x

Guidot, A., Prior, P., Schoenfeld, J., Carrere, S., Genin, S., and Boucher, C. (2007). Genomic structure and phylogeny of the plant pathogen Ralstonia solanacearum inferred from gene distribution analysis. J. Bacteriol. 189, 377-387. doi: 10.1128/JB.00999-06

Guidot, A., Coupat, B., Fall, S., Prior, P., and Bertolla, F. (2009). Horizontal gene transfer between Ralstonia solanacearum strains detected by comparative genomic hybridization on microarrays. ISME J. 3, 549-562. doi: 10.1038/ismej.2009.14

Ha, Y., Kim, J.-S., Denny, T. P., and Schell, M. A. (2012). A rapid, sensitive assay for Ralstonia solanacearum race 3 biovar 2 in plant and soil samples using magnetic beads and real-time PCR. Plant Dis. 96, 258-264. doi: 10.1094/PDIS-05-11-0426

Huang, J. H., and Schell, M. A. (1990). DNA sequence analysis of pglA and mechanism of export of its polygalacturonase product from Pseudomonas solanacearum. J. Bacteriol. 172, 3879-3887. doi: 10.1128/jb.172.7.3879-3887.1990

Inoue, Y., and Nakaho, K. (2014). Sensitive quantitative detection of Ralstonia solanacearum in soil by the most probable number-polymerase chain reaction (MPN-PCR) method. Appl. Microbiol. Biotechnol. 98, 4169-4177. doi: $10.1007 / \mathrm{s} 00253-014-5604-\mathrm{z}$

Kubota, R., and Jenkins, D. M. (2015). Real-time duplex applications of loop-mediated AMPlification (LAMP) by assimilating probes. Int. J. Mol. Sci. 16, 4786-4799. doi: 10.3390/ijms160 34786

Kubota, R., Schell, M., Peckham, G., Rue, J., Alvarez, A. M., Allen, C., et al. (2011). In silico genomic subtraction guides development of highly accurate, DNA-based diagnostics for Ralstonia solanacearum race 3 biovar 2 and blood disease bacterium. J. Gen. Plant Pathol. 77, 182-193. doi: 10.1007/s10327-0110305-2

Lane, D. J. (1991). "16S/23S rRNA sequencing," in Nucleic Acid Techniques in Bacterial Systematics, eds E. Stackebrandt and M. Goodfellow (Chichester: Wiley), 125-175. 
Lee, Y.-A., and Wang, C. C. (2000). The design of specific primers for the detection of Ralstonia solanacearum in soil samples by polymerase chain reaction. Bot. Bull. Acad. Sin. 41, 121-128.

Lefeuvre, P., Cellier, G., Remenant, B., Chiroleu, F., and Prior, P. (2013). Constraints on genome dynamics revealed from gene distribution among the Ralstonia solanacearum species. PLoS ONE 8:e63155. doi: 10.1371 /journal.pone.0063155

Lenarcic, R., Morisset, D., Pirc, M., Llop, P., Ravnikar, M., and Dreo, T. (2014). Loop-mediated isothermal amplification of specific endoglucanase gene sequence for detection of the bacterial wilt pathogen Ralstonia solanacearum. PLoS ONE 9:e96027. doi: 10.1371/journal.pone.00 96027

Li, X., Nie, J., Hammill, D. L., Smith, D., Xu, H., and De Boer, S. H. (2014). A comprehensive comparison of assays for detection and identification of Ralstonia solanacearum race 3 biovar 2. J. Appl. Microbiol. 117, 1132-1143. doi: $10.1111 /$ jam. 12585

Narayanasamy, P. (2010). Microbial Plant Pathogens-Detection and Disease Diagnosis: Bacterial and Phytoplasmal Pathogens. Dordrecht: Springer Netherlands.

Opina, N., Tavner, F., Hollway, G., Wang, J. F., Li, T. H., Maghirang, R., et al. (1997). A novel method for development of species and strain-specific DNA probes and PCR primers for identifying Burkholderia solanacearum (formerly Pseudomonas solanacearum). Asia Pac. J. Mol. Biol. Biotechnol. 5, 19-30.

Ozakman, M., and Schaad, N. W. (2003). A real-time BIO-PCR assay for detection of Ralstonia solanacearum race 3, biovar 2, in asymptomatic potato tubers. Can. J. Plant Pathol. 25, 232-239. doi: 10.1080/07060660309507075

Palmer, C., Bik, E. M., Eisen, M. B., Eckburg, P. B., Sana, T. R., Wolber, P. K., et al. (2006). Rapid quantitative profiling of complex microbial populations. Nucleic Acids Res. 34, e5. doi: 10.1093/nar/gnj007

Pelludat, C., Duffy, B., and Frey, J. E. (2009). Design and development of a DNA microarray for rapid identification of multiple European quarantine phytopathogenic bacteria. Eur. J. Plant Pathol. 125, 413-423. doi: 10.1007/s10658-009-9490-7

Prior, P., and Fegan, M. (2005a). "Diversity and molecular detection of Ralstonia solanacearum race 2 strains by multiplex PCR," in Bacterial Wilt Disease and the Ralstonia solanacearum Species Complex, eds C. Allen, P. Prior, and A. C. Hayward (St. Paul: APS Press), 405-414.

Prior, P., and Fegan, M. (2005b). Recent developments in the phylogeny and classification of Ralstonia solanacearum. Acta Hortic. 695, 127-136. doi: 10.17660/ActaHortic.2005.695.14

Prior, P., Ailloud, F., Dalsing, B. L., Remenant, B., Sanchez, B., and Allen, C. (2016). Genomic and proteomic evidence supporting the division of the plant pathogen Ralstonia solanacearum into three species. BMC Genomics 17:90. doi: $10.1186 / \mathrm{s} 12864-016-2413-\mathrm{z}$

R Development Core Team (2011). R: A Language and Environment for Statistical Computing. Vienna: R Foundation for Statistical Computing. Available online at: http://www.R-project.org/

Rouillard, J. M., Zuker, M., and Gulari, E. (2003). OligoArray 2.0: design of oligonucleotide probes for DNA microarrays using a thermodynamic approach. Nucleic Acids Res. 31, 3057-3062. doi: 10.1093/nar/gkg426

Safni, I., Cleenwerck, I., De Vos, P., Fegan, M., Sly, L., and Kappler, U. (2014). Polyphasic taxonomic revision of the Ralstonia solanacearum species complex: proposal to emend the descriptions of Ralstonia solanacearum and Ralstonia syzygii and reclassify current $R$. syzygii strains as Ralstonia syzygii subsp. syzygii subsp. nov., $R$. solanacearum phylotype IV strains as Ralstonia syzygii subsp. indonesiensis subsp. nov., banana blood disease bacterium strains as Ralstonia syzygii subsp. celebesensis subsp. nov. and R. solanacearum phylotype I and III strains as Ralstonia pseudosolanacearum sp. nov. Int. J. Syst. Evol. Microbiol. 64, 3087-3103. doi: 10.1099/ijs.0.066712-0

Schmoock, G., Ehricht, R., Melzer, F., Elschner, M., Tomaso, H., Neubauer, H., et al. (2011). Development of a diagnostic multiplex polymerase chain reaction microarray assay to detect and differentiate Brucella spp. Diagn. Microbiol. Infect. Dis. 71, 341-353. doi: 10.1016/j.diagmicrobio.2011.08.013
Schneeberg, A., Ehricht, R., Slickers, P., Baier, V., Neubauer, H., Zimmermann, S., et al. (2015). DNA microarray-based PCR ribotyping of Clostridium difficile. J. Clin. Microbiol. 53, 433-442. doi: 10.1128/JCM.02524-14

Schonfeld, J., Heuer, H., Van Elsas, J. D., and Smalla, K. (2003). Specific and sensitive detection of Ralstonia solanacearum in soil on the basis of PCR amplification of fliC fragments. Appl. Environ. Microbiol. 69, 7248-7256. doi: 10.1128/AEM.69.12.7248-7256.2003

Seal, S. E., Jackson, L. A., Young, J. P., and Daniels, M. J. (1993). Differentiation of Pseudomonas solanacearum, Pseudomonas syzygii, Pseudomonas pickettii and the Blood Disease Bacterium by partial 16S rRNA sequencing: construction of oligonucleotide primers for sensitive detection by polymerase chain reaction. $J$. Gen. Microbiol. 139, 1587-1594. doi: 10.1099/00221287-139-7-1587

Smith, D. S., and De Boer, S. H. (2009). Implementation of an artificial reaction control in a TaqMan method for PCR detection of Ralstonia solanacearum race 3 biovar 2. Eur. J. Plant Pathol. 124, 405-412. doi: 10.1007/s10658-008-9427-6

Stulberg, M. J., and Huang, Q. (2015). A TaqMan-based multiplex qPCR assay and DNA extraction method for Phylotype IIB sequevars 1\&2 (select agent) strains of Ralstonia solanacearum. PLoS ONE 10:e0139637. doi: 10.1371/journal.pone.0139637

Stulberg, M. J., Shao, J., and Huang, Q. (2015). A multiplex PCR assay to detect and differentiate select agent strains of Ralstonia solanacearum. Plant Dis. 99, 333-341. doi: 10.1094/PDIS-05-14-0483-RE

Taghavi, M., Hayward, C., Sly, L. I., and Fegan, M. (1996). Analysis of the phylogenetic relationships of strains of Burkholderia solanacearum, Pseudomonas syzygii, and the blood disease bacterium of banana based on 16S rRNA gene sequences. Int. J. Syst. Bacteriol. 46, 10-15. doi: 10.1099/00207713-46-1-10

Tan, P. H. L. (2003). The Blood Disease Bacterium: Exploiting Geneticdiversity for the Development of a Molecular Diagnostic Test. BS (Hons) thesis, University of Queensland, Brisbane, QLD.

Tomlinson, J., Harrison, C., Boonham, N., Goodchild, S. A., and Weller, S. A. (2014). Influence of the length of target DNA overhang proximal to the array surface on discrimination of single-base mismatches on a 25 -mer oligonucleotide array. BMC Res. Notes 7:251. doi: 10.1186/1756-0500-7-251

Untergasser, A., Cutcutache, I., Koressaar, T., Ye, J., Faircloth, B. C., Remm, M., et al. (2012). Primer3-new capabilities and interfaces. Nucleic Acids Res. 40, e115. doi: 10.1093/nar/gks596

Vallenet, D., Engelen, S., Mornico, D., Cruveiller, S., Fleury, L., Lajus, A., et al. (2009). MicroScope: a platform for microbial genome annotation and comparative genomics. Database 2009:bap021. doi: 10.1093/database/bap021

Villa, J., Tsuchiya, K., Horita, M., Natural, M., Opina, N., and Hyakumachi, M. (2003). DNA analysis of Ralstonia solanacearum and related bacteria based on 282-bp PCR-amplified fragment. Plant Dis. 87, 1337-1343. doi: 10.1094/PDIS.2003.87.11.1337

Weller, S. A., Elphinstone, J. G., Smith, N. C., Boonham, N., and Stead, D. E. (2000). Detection of Ralstonia solanacearum strains with a quantitative, multiplex, real-time, fluorogenic PCR (TaqMan) assay. Appl. Environ. Microbiol. 66, 2853-2858. doi: 10.1128/AEM.66.7.2853-2858.2000

Wicker, E., Grassart, L., Coranson-Beaudu, R., Mian, D., and Prior, P. (2009). Epidemiological evidence for the emergence of a new pathogenic variant of Ralstonia solanacearum in Martinique (French West Indies). Plant Pathol. 58, 853-851. doi: 10.1111/j.1365-3059.2009.02098.x

Conflict of Interest Statement: The authors declare that the research was conducted in the absence of any commercial or financial relationships that could be construed as a potential conflict of interest.

Copyright () 2017 Cellier, Arribat, Chiroleu, Prior and Robène. This is an open-access article distributed under the terms of the Creative Commons Attribution License (CC $B Y)$. The use, distribution or reproduction in other forums is permitted, provided the original author(s) or licensor are credited and that the original publication in this journal is cited, in accordance with accepted academic practice. No use, distribution or reproduction is permitted which does not comply with these terms. 